\title{
A comparative evaluation of kambin's triangle approach versus safe triangle approach for lumbar transforaminal epidural injection in patients with lumbar radiculopathy - A prospective, randomized, double blind study
}

\author{
Rajasree Biswas ${ }^{1}$, Arpita Choudhury², Dipasri Bhattacharya ${ }^{3}$, Sabyasachi Nandy ${ }^{4}$ \\ ${ }^{1}$ Associate Professor, ${ }^{2}$ Assistant Professor, ${ }^{3}$ Professor and Head, Department of Anaesthesiology and Critical Care \\ Medicine and Pain management, R G Kar Medical College and Hospital, Kolkata, West Bengal, India \\ ${ }^{4}$ Consultant Anaesthesiologist and Pain Physician
}

\section{A B S T R A C T}

Background: Epidural injection of steroid and local anaesthetic is a common modality for management of radicular pain. Transforaminal approach is preferred for epidural injection in case of radiculopathy. Aims and Objectives: To compare the effect of the Kambin's triangle and subpedicular approaches of transforaminal epidural injection (TFEI) in patients of lumbar radiculopathy. Materials and Methods: Forty patients with lumbar radicular pain were enrolled and randomly assigned to each group (Group K for Kambin's triangle approach and Group S for subpedicular approach). All procedures were performed under fluroscopic guidance. The frequency of complications during the procedure and the effect of TFEl at 2 and 4 weeks after the procedure between the two groups were compared. Short-term outcomes were measured using a visual Analog scale (VAS). Multiple logistic regression analyses were performed to evaluate the relationship between possible outcome predictors and the therapeutic effect. Result: VAS was improved 2 weeks after the injection and continued to improve until 4 weeks in both groups. There were no statistical differences in changes of VAS between these two groups. Spinal nerve pricking occurred in one case of the subpedicular and in none of the cases of the Kambin's triangle approach $(p<0.05)$. Conclusion: Kambin's triangle approach is as efficacious as the subpedicular approach for short-term effect and offers considerable advantages (i.e., less spinal nerve pricking during procedure). So, Kambin's triangle approach may be an alternative method for TFEI in cases where needle tip positioning in the anterior epidural space is difficult.

Key words: Kambin's triangle; Subpedicular approach; Lumbar radiculopathy;

Transforaminal epidural injection

\section{INTRODUCTION}

Lumbar spinal stenosis affects significant number of adult population (more than 200000 adults in the United States yearly) causing radiculopathy leading to neuropathic radiating pain in the lower limbs. It is mostly due to narrowed intervertebral foramen by a herniated intervertebral disc, degenerative changes and thickening of the ligamentum flavum, zygapophysial joint and surrounding soft tissues. ${ }^{1-3}$ In addition to mechanical compression, causes of radicular pain include inflammatory changes around nerve root, venous congestion and haematogenous disability. ${ }^{4,5}$ Injection of steroid and local anaesthetic is a common modality for management of radicular pain due to nerve root compression in spinal stenosis. Proposed mechanisms of pain relief by injected 
epidural steroids in spinal stenosis includes interruption in the synthesis of prostaglandins, conduction blockade of nociceptive $\mathrm{C}$ fibers and reduction of edema around the nerve root. ${ }^{6-8}$ Instead of conventional approach for epidural anaesthesia or analgesia, transforaminal approach is preferred for epidural injection in case of radiculopathy, as injection near the relevant nerve root may maximize drug concentration around the nerve and it is also possible to inject toward the anterior extradural space. ${ }^{9,10}$ At present, the subpedicular approach or Safe triangle approach (Figure. 1) is the most commonly used method of Transforaminal epidural injection (TFEI). In this method, the injection needle is advanced towards the safe triangle under the inferior surface of the pedicle. ${ }^{11}$ This location is preferred because agents can be injected into the anterior epidural space, between the posterior surface of the herniated intervertebral disc and the anterior nerve root dural sleeve which is the usual site of inflammation. In this approach, the agents are injected at the exit zone as the distal site of the nerve root canal. Such approaches may damage the intervertebral disc because the injection is adjacent to the posterior segment of the intervertebral disc. Thus, in this study, the final target site of injection was determined to be the posterior inferior at the lateral view (Figure. 2).

As the needle proceeds through the upper-lateral border of the intervertibral foramen, the risk of damaging dura though present, is said to be less. ${ }^{9-12}$ Also, the Adamkiewicz artery (AKA artery) runs through the safe triangle and injection at this site may damage the artery or can transfer agents within the artery causing arterial thrombosis with catastrophic consequences. ${ }^{13}$

In 1972, Kambin introduced posterolateral approach for endoscopic discectomy, defining the Kambin's triangle as the site to approach the intervetebral disc. ${ }^{14}$ The Kambin's triangle is defined as a right triangle over the dorsolateral disc. The hypotenuse is the exiting nerve root, the base (width) is the superior border of the caudal vertebra and the height is the dura/traversing nerve root (Figure 3). ${ }^{14}$ This approach is claimed to prevent chronic nerve edema, epidural bleeding and epidural scarring. ${ }^{15,16}$ Thus, it is said to be safer for transforaminal epidural injection. There are many transforaminal approaches using this site, including the retro discal approach ${ }^{17}$ and the preganglionic approach. ${ }^{18}$ Nerve root canal, which is defined as the space that the nerve root occupies from where it is visible to where it leaves the intervertebral foramen, is divided into the entrance, middle and exit zone. The space occupied by the spinal nerve outside the exit zone is called the far lateral zone. ${ }^{19}$

When the radiculomedullary artery was located by spinal angiography in the intervertebral foramen, $97 \%$ of the

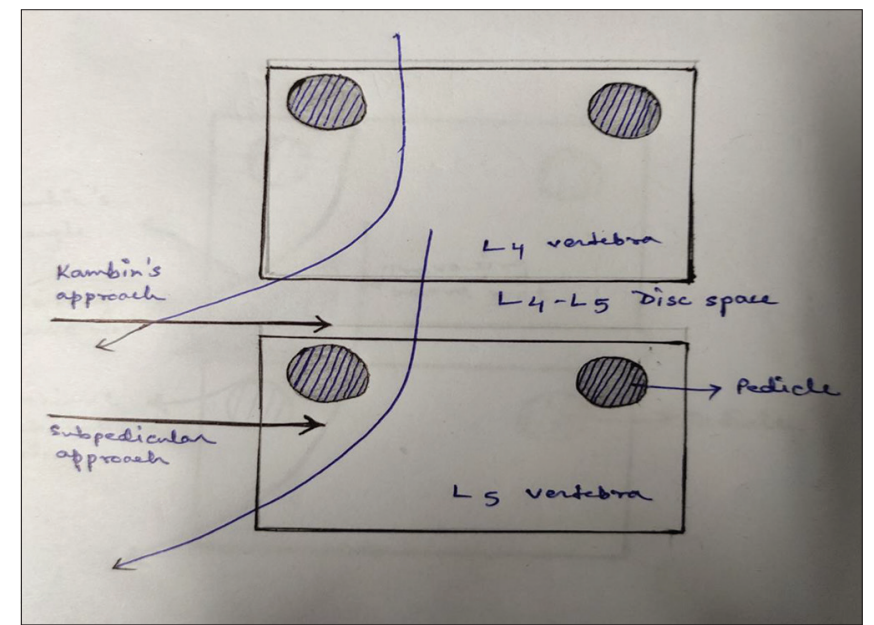

Figure 1: Schematic description for transforaminal epidural steroid injection with the Kambin's triangle versus the subpedicular approach (target L5 nerve root). (Concept taken from Park J W, Nam S H, Cho S K, Jung H J, Lee B J, Park Y. Kambin's triangle approach of lumbar transforaminal epidural injection with spinal stenosis. Ann Rehabilitation Med. 2011 Dec; 35(6):833-843.)

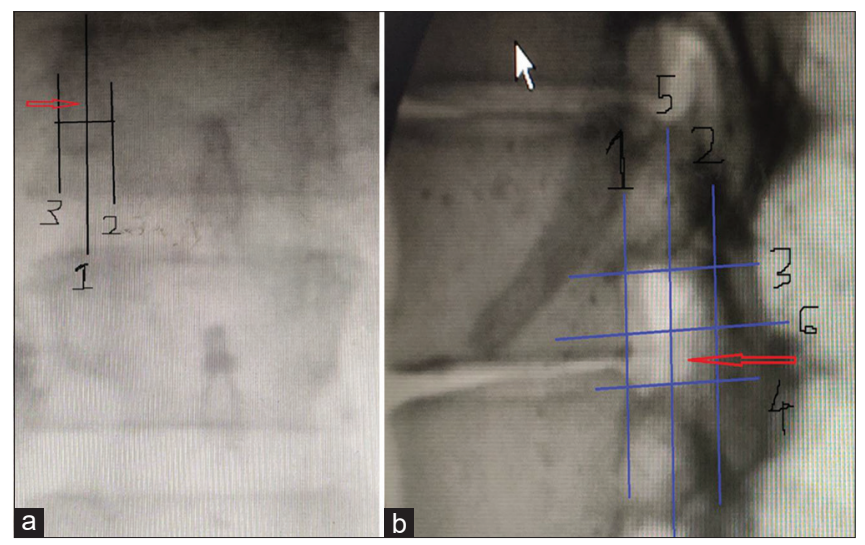

Figure 2: (a) Anterior-posteior view of the lumbar spine, with superimposed line (1) bisecting the pedicle. This line was drawn halfway between the farthest medial (2) and farthest lateral (3) points on the pedicle. (b) Lateral view of the lumbar spine, with the quadrant system superimposed. First, a line was drawn tangent to the curve of the spine at the level of interest along the posterior vertebral line. (1) A second line (2) was drawn parallel to the third at the posterior margina of the foramen. Next, two lines perpendicular to lines 1 and 2 were drawn at the superior and inferior margins of the foramen ( 3 and 4 , respectively). Finally, line 5 was drawn bisecting 1 and 2, and, likewise, line 6 bisecting 3 and 4 . This divided the foramen into four quadrants Arrow: needle position. (Photographs taken in the procedure room) (Concept taken from Park J W, Nam S H, Cho S K, Jung H J, Lee B J, Park Y. Kambin's triangle approach of lumbar transforaminal epidural injection with spinal stenosis. Ann Rehabilitation Med. 2011 Dec; 35(6): 833-843.)

cases showed that the artery was located on the upper half of the intervertebral foramen. No artery was found in the area of less than $20 \%$ of the intervertebral foramina and if injection needle is located in that area, the risk of injecting agents into radiculomedullary artery is less and thus vessel damage could be prevented. ${ }^{13}$ 


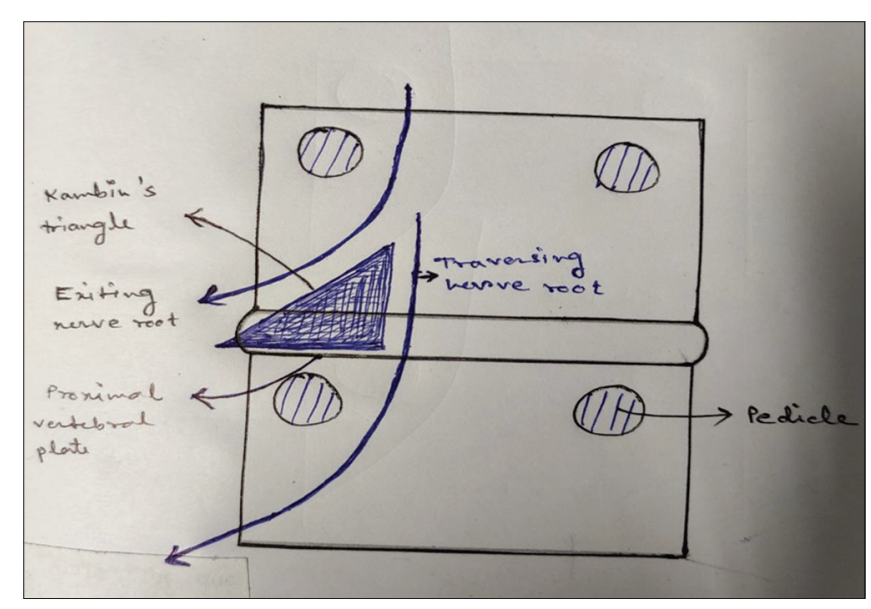

Figure 3: Schematic description of the "Kambin's triangle". The triangle is defined by the hypotenuse, base, and height. The hypotenuse is the exiting nerve; the base is the caudad vertebral body; and the height is the traversing nerve root. (Concept taken from Park J W, Nam S $\mathrm{H}$, Cho S K, Jung H J, Lee B J, Park Y. Kambin's triangle approach of lumbar transforaminal epidural injection with spinal stenosis. Ann Rehabilitation Med. 2011 Dec; 35(6) : 833-843.)

\section{AIMS AND OBJECTIVES}

1. Primary objective: to compare the fluoroscopy guided subpedicular approach and the approach using Kambin's triangle of TFEI performed in patients with spinal stenosis complaining of lumbar radicular pain and possible complications during injection

2. Secondary objective was to investigate and compare the post procedure effects for both the approach.

\section{MATERIALS AND METHODS}

The study was conducted in the pain clinic and operation theater in R G KAR Medical College and Hospital under Department of Anaesthesiology and Pain Management between October 2020 to February 2021. Patients of lumbar radiculopathy diagnosed by history, clinical examination, electromyography and/or patients with spinal stenosis causing compression on the relevant nerve root evidenced by lumbar computed tomography (CT) and/or magnetic resonance imaging (MRI) were included in the study. Patients with generalized inflammatory diseases, patients on anticoagulant agents, uncontrollable diabetes, previous history of adverse effects to lidocaine and/or contrast agents, current suspected or diagnosed infection, poor general health, difficulty in visiting the hospital regularly, cutaneous disorders around the injection site, mental problems preventing the patient to answer the questionnaire, previous injection treatment at the same site within the past three months, patients requiring constant drug administration or treatment during the study period, using analgesics and anti-inflammatory agents (except for acetaminophen or physiotherapy) and patients with cauda equine syndrome were excluded from the study. After collecting information on basic patient characteristics, the subjects $(n=40)$ were randomly divided into two groups with respect to the approach: Subpedicular approach $(n=20)$; or Kambin's triangle approach $(n=20)$ using computer generated randomization table

\section{METHOD OF INJECTION}

\section{Kambin's triangle approach}

Patients were placed in prone position and a pillow was placed under the abdomen to reduce the lumbar lordosis. The $\mathrm{X}$ ray projection from the fluoroscope was focused on the epiphyseal plate of the upper and lower vertebral body by the cranial-caudal tilt of the $\mathrm{C}$-arm. Then the C-arm was rotated by 20-35 degrees obliquely toward the region, so that the superior articular process could be seen at the middle of the intervertebral disc. The needle entry site was marked, disinfected, draped and infiltrated with local anaesthetic. At that location, a 3.5inch 22 Gauge spinal needle was inserted into the skin toward the lateral lower part of the superior articular process and parallel to the X-ray projection path. When the process was touched, the needle was directed laterally and advanced by $2-3 \mathrm{~mm}$. Finally, the needle was placed medially in the 5 o'clock position to the upper pedicle in AP (anteroposterior) view and in the posteroinferior part of the intervertebral foramen in lateral view. After securing the final position of the needle, $1 \mathrm{cc}$ of nonionic contrast agent was administered to observe diffusion and location of the contrast agent, and then $2 \mathrm{cc}$ of the prepared agent $(0.5 \%$ lidocaine $1.5 \mathrm{ml}+$ triamcinolone $20 \mathrm{mg}$ ) was injected.

\section{Subpedicular approach}

All patients were put in the prone position with a pillow under the abdomen to reduce lumbar lordosis. The relevant lumbar part was identified by using the Scotty dog shadow oblique view. For this, the lower endplate of the spine for the $\mathrm{C}$-arm was adjusted for accordance and rotated by 15-30 degrees in the oblique view to visualize the Scotty dog shadow. After the site of entry is identified and marked, antiseptic dressing and draping was done. Local anaesthetic infiltration to skin of the entry site done. A 3.5-inch 22 Gauge spinal needle was advanced toward the subjacent pedicle, inferolateral interarticularis (safe triangle) of the superior part of the intervertebral foramen. Then the C-arm was rotated to the lateral view, when the tip of the needle reached the inferolateral border. Then the needle was advanced gradually toward the anterosuperior aspects of the intervertebral foramen. After securing 
the final location of the needle, an aspiration test was conducted to exclude intravascular needle placement and $1 \mathrm{cc}$ of non-ionic contrast agent was injected under realtime fluoroscopy to identify the spread of the contrast agent into the anterior epidural space. Then $2 \mathrm{cc}$ of the agent $(0.5 \%$ lidocaine $1.5 \mathrm{ml}+$ triamcinolone $20 \mathrm{mg})$ was injected.

\section{Assessment of variables}

All events were recorded during and after injections. The advantages and disadvantages of the two methods were compared by observing diffusion location and scope of the injected agents, and the discomfort produced by injection. When the agent diffused into the epidural space, diffusion to the anterior or posterior epidural space was analyzed on the lateral view. The spinal levels of diffusion of the contrast agent in the cranial-caudal direction in the epidural space were assessed in AP view.

Pain was assessed before treatment and 2 and 4 weeks after treatment, to compare the short-term therapeutic effects of the two approaches using Visual Analog Scale (VAS) where 0 means no pain and $10(\mathrm{~cm})$ means worst pain.

\section{Statistical analysis}

Gender, BMI, period of prevalence, age, targeted nerve root and diffusion of the contrast agent were compared between the two groups using the chi-square test, Fisher's exact test, and Mann-Whitney U test. Comparison between the two groups in complications and discomfort that could occur during injection were conducted by Fisher's exact test. Comparison of the visual analog scale (VAS) between the two groups was conducted by repeated measures analysis of variance (ANOVA), and Bonferroni's correction was applied post-hoc. SAS Enterprise Guide 4.1 (4.1.0.471) software was used for statistical analysis, and statistical significance level was set at $\mathrm{p}<0.05$.

\section{RESULTS}

Table 1 shows the demographic distribution of both the groups. We started with 46 patients. Three patients were found to have any of the exclusion criteria and were excluded. Two patients in kambin's triangle approach group and one patient in subpedicular approach group denied procedure. So we were left with 40 patients, 20 in each group. As per age, sex BMI and duration of symptoms, both the groups were comparable with no significant $\mathrm{p}$ value. As per nerve root involvement, both the groups were comparable too.

There were no significant difference between baseline pain (VAS score) among both the groups. After injection pain

\begin{tabular}{lccc}
\multicolumn{4}{l}{ Table 1: Demographic variable } \\
\hline & $\begin{array}{c}\text { Subpecular } \\
\text { approach } \\
(\mathbf{n}=\mathbf{2 0})\end{array}$ & $\begin{array}{c}\text { Kambin's } \\
\text { triangle } \\
\text { approach }(\mathbf{n}=\mathbf{2 0})\end{array}$ & $\begin{array}{c}\mathbf{P} \\
\text { value }\end{array}$ \\
\hline Age (years) & $\begin{array}{c}64.31 \pm 5.69 \\
8 / 12\end{array}$ & $\begin{array}{c}67.15 \pm 4.21 \\
9 / 11\end{array}$ & 0.251 \\
Sex(M/F) & $24.1 \pm 0.71$ & $23.8 \pm 1.53$ & 0.508 \\
BMI (Kg/square & & & 0.680 \\
meters) & & $7.11 \pm 2.46$ & 0.591 \\
Duration (month) & $6.51 \pm 3.10$ & & \\
Target root- & & 2 & \\
L2 & 3 & 1 & \\
L3 & 2 & 9 & 0.892 \\
$\quad$ L4 & 8 & 8 & \\
L5 & 7 & &
\end{tabular}

decreased significantly in both the groups at 2 weeks as well as 4 weeks (Table 2).

Nerve root pricking during injection showed no significant differences: one case was reported in the subpedicular approach, whereas no case was found in the Kambin's triangle approach. As for intravascular injection, no case was found in either of the group. (Table 3). Both groups did not present nerve root damage as a complication, and injection into the intervertebral disc was found in two cases of the subpedicular approach and one case in kambin's triangle approach, though there was no significant difference among the groups. Patients with dizziness and temporary muscular weakness were moved to the recovery room for observation and all symptoms were absent at discharge. The patient with nerve root pricking did not show nerve root damage at the 2 -week follow-up visit.

In subpedicular approach, in AP view, the dye distribution was $1.61 \pm 0.72$ segments in cephalocaudal direction, whereas it was $1.58 \pm 0.59$ segments in case of Kambin's triangle approach. There was no significant difference between the two groups with respect to cephalocaudal dye distribution (Table 4). In lateral view also the dye distribution was comparable.

\section{DISCUSSION}

Spinal nerve root compression in the spinal canal or nervous canal leading to neuropathic pain can occur due to various reasons including prolapsed intervertebral disc, vertebral fracture, thickened zygopophysial joint and ligamentum flavum, ossification of posterior longitudinal ligament etc. ${ }^{1-3}$ Factors like narrowing of spinal canal by congenital or degenerative causes or spondyloysis and venous congestion may also cause nerve root compression. Increased permeability of the cell membrane produced by nutritional disorder and inflammatory mediators may induce edema in the nerve root, leading to pain and 


\section{Table 2: Comparison of the effect of steroid injection on VAS}

\begin{tabular}{lccc} 
& Baseline & 2 weeks after injection & 4 weeks after injection \\
\hline Subpedicular approach & $7.9 \pm 0.41$ & $3.10 \pm 0.51(p=0.03)$ & $2.03 \pm 0.53(p=0.039)$ \\
Kambin's triangle approach & $7.68 \pm 0.21$ & $2.95 \pm 0.3(p=0.04)$ & $2.13 \pm 0.49(p=0.028)$ \\
\hline Values are represented as mean $\pm S D$ or percentage & & &
\end{tabular}

\begin{tabular}{lccc} 
Table 3: Complications during injection & \\
\hline & $\begin{array}{c}\text { Subpedicular } \\
\text { approach }\end{array}$ & $\begin{array}{c}\text { Kambin's triangle } \\
\text { approach }\end{array}$ & P value \\
\hline $\begin{array}{l}\text { Spinal nerve } \\
\text { pricking } \\
\text { Intra vascular } \\
\text { injection } \\
\text { Discal injection }\end{array}$ & 1 & 0 & 0.512 \\
\hline
\end{tabular}

\section{Table 4: Spread of contrast in study patients}

\begin{tabular}{lccc}
\hline & $\begin{array}{c}\text { Subpedicular } \\
\text { approach }\end{array}$ & $\begin{array}{c}\text { Kambin's triangle } \\
\text { approach }\end{array}$ & P value \\
\hline $\begin{array}{l}\text { Cephalad } \\
\text { spreading } \\
\text { segments }\end{array}$ & $1.12 \pm 0.49$ & $1.29 \pm 0.46$ & 0.39 \\
$\begin{array}{l}\text { Caudal } \\
\text { spreading }\end{array}$ & $1.49 \pm 0.25$ & $1.39 \pm 0.37$ & 0.210 \\
$\begin{array}{l}\text { segments } \\
\text { Total } \\
\text { spreading } \\
\text { segments }\end{array}$ & $1.61 \pm 0.72$ & $1.58 \pm 0.59$ & 0.476 \\
\hline $\begin{array}{l}\text { Values are represented as mean } \pm \text { SD or percentage } \\
\end{array}$
\end{tabular}

numbness in the region of distribution of the respective nerve. ${ }^{4}$ A good number of patients with neuropathic pain due to nerve root compression can be treated by drugs, epidural nerve block and kinesitherapy, and surgery can be avoided. Delport et al., reported that steroid injection using the caudal approach and transforaminal approach alleviated pain in a third of the subjects and half of the patients had improvement in functions. ${ }^{20}$ Riew et al., ${ }^{21}$ in their prospective, double-blind, randomly-assigned study showed that, in patients with spinal stenosis, steroid injection using transforaminal approach by the C-arm showed clinical improvements during the observation period (15-28 months). Transforaminal approach is preferred over conventional midline approach because the injected drug can easily reach the targeted nerve root, dorsal root ganglion and the anterior of epidural space and thus small amount of local anaesthetic and steroid can produce the desired effect. ${ }^{22,23}$ However, the transforaminal approach may lead to severe complications during and after the procedure, including injury to vessel or nerve by the needle, convulsions and cardiac arrhythmias due to intravascular injection of local anaesthetic, embolism due to injection of steroids particularly particulate steroids into vessels followed by ischemic neurological damage of the vessel's supply area, etc. ${ }^{24,25}$ Glaser and Falco reported lower limb paralysis by ischemic spinal damage after lumbar, dorsal and intervertebral foramen steroid epidural injection, even when the needle was located in the safe triangle reaching via subpedicular approach. ${ }^{25}$ These reports raised the concern and led the search for safer approach for transforaminal epidural injection. ${ }^{26}$

The safe triangle for transforaminal epidural injection mainly contains only the spinal nerve and vessels. ${ }^{11}$ So there is the probability of pricking the nerve or the vessel with the needle leading to nerve or vessel injury and there is chance of injecting the drugs in the vessel also. As the injection needle is placed in the anterosuperolateral aspect of the intervertebral foramen, the TFEI by subpedicular approach is likely to injure blood vessels such as the $\mathrm{AKA}^{26}$ or can cause complications, such as spinal cord infarction resulting from the intravascular injection of particulate steroids. Approaching the same area with the needle directing towards the lower part also didn't help due to the presence of posteromedial venous plexus in that area keeps the chance of intravascular injection. ${ }^{8}$

The Kambin's triangle is situated over the dorsolateral disc. Transforaminal epidural injection at this place have many advantages, including enhanced safety. There are several methods of transforaminal epidural injections such as preganglionic and retro discal approaches. ${ }^{17,18}$ However, there is higher risk for injection of contrast agent into the intervertebral disc in retro discal approach because the contrast agent is injected near the disc that may cause diskitis as complication. Therefore it is preferred to place the needle in the posteroinferior part of the intervertebral foramen on the lateral view. We also placed the needle in this location. As a result, two cases of injecting the contrast agent into the intervertebral disc were found in the subpedicular approach, but only one case in the Kambin's triangle approach. Any patients did not develop diskitis.

Previously, it was assumed that the TFEI through Kambin's triangle approach would provide reduced therapeutic effects, as the agent was injected into the lateral epidural space. But as in the study of Park et al., ${ }^{27}$ the present study also found no statistical difference between the two methods in terms of therapeutic efficacy. The agent was found to be sufficiently injected to the target area in fluoroscopic imaging, as the agent diffused to the anterior epidural space seen on AP (anteroposterior) and lateral view. In a retrospective study, Crall et al., reported no statistical 
differences in the immediate effects from injections into four parts of the intervertebral foramen, noting that the Kambin's triangle approach did not show difference or superiority in treatment effects when compared to the existing subpedicular approach. ${ }^{28-30}$ According to Jeong et al. the Kambin's triangle approach was superior to the subpedicular approach in treatment efficacy after 4 weeks of the injection, a result that may have been caused by the fact that the clinical group had more patients with herniated intervertebral disc than patients with spinal stenosis. ${ }^{30}$ In our study also we did not find any significant difference, both in treatment effectiveness and complications.

In the subpedicular approach, the needle is placed in the anterior part of the intervertebral foramen after crossing the nerve root. So, spinal nerve root may be pricked or injured during needle placement because it is difficult to place the needle in the anterior epidural space through the safe triangle in patients with severe spinal stenosis, epidural fibrosis, and sunken degenerative intervertebral disc disease. On the other hand, in the Kambin's triangle approach, the needle is placed in the infero-posterior part in lateral view, thus reducing the risk of pricking the spinal nerve root. Hoshide R et al performed cadaveric analysis of dimensions of kambin's triangle and found it to be safe for needle entry. ${ }^{31}$ Gil HY et al., showed that kambin's triangle approach can be beneficial in patients where entry through safe triangle is difficult. ${ }^{32}$ In our study, there was a single case of spinal nerve root pricking in the subpedicular approach whereas no pricking was reported in the Kambin's triangle approach but this difference was not statistically significant.

We compared the treatment effects and functional effects of the Kambin's triangle and the subpedicular approach for four weeks and also compared the complications and benefits/weaknesses during injection and upto four weeks. As this study compared only the short-term effects for four weeks, it is needed to compare long-term treatment effects for at least six months in the future.

\section{CONCLUSIONS}

Kambin's triangle approach can be an alternative to subpedicular approach for transforaminal epidural injection. It can be helpful in cases where reaching the epidural space is difficult via subpedicular approach like severe spinal stenosis, epidural fibrosis and sunken degenerative intervertebral disc lesion. Complications like nerve root pricking, intravascular or intradiscal injection during the procedure were comparable in both the approaches and post procedure outcome in terms of pain reduction is also comparable in both the approaches.

\section{ACKNOWLEDGEMENT}

The authors wish to thank all the participating investigators and patients for their contributions to this study.

\section{REFERENCE}

1. Grubb SA, Lipscomb HJ and Coonrad RW. Degenerative adultonset scoliosis. Spine. 1988; 13:241-245.

https://doi.org/10.1097/00007632-198803000-00004

2. Jackson RP and McManus AC. Radiographic analysis of sagittal plane alignment and balance in standing volunteers and patients with low back pain matched for age, sex, and size. A prospective controlled clinical study. Spine. 1994; 19:1611-1161. https://doi.org/10.1097/00007632-199407001-00010

3. Grubb SA, Lipscomb HJ and Suh PB. Results of surgical treatment of painful adult scoliosis. Spine (Phila Pa 1976) 1994; $15: 1619-1627$.

https://doi.org/10.1097/00007632-199407001-00011

4. Olmarker K, Redevik B and Holm S. Edema formation in spinal nerve roots induced by experimental, graded compression. An experimental study on the pig cauda equina with special reference to differences in effects between rapid and slow onset of compression. Spine. 1989; 14:569-573.

https://doi.org/10.1097/00007632-198906000-00003

5. Rydevik B, Brown MD and Lundborg G. Pathoanatomy and pathophysiology of nerve root compression. Spine. 1984; 9:7-15. https://doi.org/10.1097/00007632-198401000-00004

6. Johansson A, Hao J and Sjolund B. Local corticosteroid application blocks transmission in normal nociceptive C-fibres. Acta Anaesthesiol Scand. 1990; 34:335-338.

https://doi.org/10.1111/j.1399-6576.1990.tb03097.x

7. Kantrowitz F, Robinson DR, McGuire MB and Levine L. Corticosteroids inhibit prostaglandin production by rheumatoid synovia. Nature. 1975; 258:737-739. https://doi.org/10.1038/258737a0

8. Fukusaki M, Kobayashi I, Hara T and Sumikawa K. Symptoms of spinal stenosis do not improve after epidural steroid injection. Clin J Pain. 1998; 14:148-151.

https://doi.org/10.1097/00002508-199806000-00010

9. Vad VB, Bhat AL, Lutz GE and Cammisa F. Transforaminal epidural steroid injections in lumbosacral radiculopathy: a prospective randomized study. Spine. 2002; 27:11-16.

https://doi.org/10.1097/00007632-200201010-00005

10. Slipman CW and Chow DW. Therapeutic spinal corticosteroid injections for the management of radiculopathies. Phys Med Rehabil Clin N Am. 2002; 13:697-711. https://doi.org/10.1016/S1047-9651(02)00004-9

11. Manchikanti L, Cash KA, Pampati V, Damron KS and McManus $\mathrm{CD}$. Evaluation of lumbar transforaminal epidural injections with needle placement and contrast flow patterns: a prospective, descriptive report. Pain Physician. 2004; 7:217-223.

https://doi.org/10.36076/ppj.2004/7/217

12. Botwin KP, Gruber RD, Bouchlas CG, Torres-Ramos FM, Sanelli JT, Freeman ED, et al. Fluoroscopically guided lumbar transforaminal epidural steroid injections in degenerative lumbar stenosis: an outcome study. Am J Phys Med Rehabil. 2002; 81:898-905.

https://doi.org/10.1097/00002060-200212000-00003

13. Murthy NS, Maus TP and Behrns CL. Intraforaminal location of the 
great anterior radiculomedullary artery (artery of Adamkiewicz): a retrospective review. Pain Med. 2010; 11:1756-1764. https://doi.org/10.1111/j.1526-4637.2010.00948.x

14. Kambin $P$ and Sampson S. Posterolateral percutaneous suction-excision of herniated lumbar intervertebral discs. Report of interim results. Clin Orthop Relat Res. 1986; 207:37-43. https://doi.org/10.1097/00003086-198606000-00008

15. Kambin P. Arthroscopic microdiskectomy. Mt Sinai J Med. 1991; 58:159-164.

16. Kambin $\mathrm{P}$ and Savitz $\mathrm{MH}$. Arthroscopic microdiscectomy: an alternative to open disc surgery. Mt Sinai J Med. 2000; 67:283-287.

17. Jasper JF. Lumbar retrodiscal transforaminal injection. Pain Physician. 2007; 10:501-510. https://doi.org/10.36076/ppj.2007/10/501

18. Lew HL, Coelho $\mathrm{P}$ and Chou LH. Preganglionic approach to transforaminal epidural steroid injections. Am J Phys Med Rehabil. 2004; 83:378. https://doi.org/10.1097/00002060-200405000-00008

19. Lee CK, Rauschning $W$ and Glenn W. Lateral lumbar spinal canal stenosis: classification, pathologic anatomy and surgical decompression. Spine. 1988; 13:313-320.

https://doi.org/10.1097/00007632-198803000-00015

20. Delport EG, Cucuzzella AR, Marley JK, Pruitt CM and Fisher JR. Treatment of lumbar spinal stenosis with epidural steroid injections: a retrospective outcome study. Arch Phys Med Rehabil. 2004; 85:479-484.

https://doi.org/10.1016/S0003-9993(03)00472-6

21. Riew KD, Yin Y, Gilula L, Bridwell KH, Lenke LG, Lauryssen $C$, et al. The effect of nerve-root injections on the need for operative treatment of lumbar radicular pain. A prospective, randomized, controlled, double-blind study. J Bone Joint Surg Am. 2000; 82:1589-1593.

https://doi.org/10.2106/00004623-200011000-00012

22. Boswell MV, Hansen HC, Trescot AM and Hirsch JA. Epidural steroids in the management of chronic spinal pain and radiculopathy. Pain Physician. 2003; 6:319-334. https://doi.org/10.36076/ppj.2003/6/319

23. Manchikanti L. Transforaminal lumbar epidural steroid injections. Pain Physician. 2000; 3:374-398. https://doi.org/10.36076/ppj.2000/3/374
24. Houten JK and Errico TJ. Paraplegia after lumbosacral nerve root block: report of three cases. Spine J. 2002; 2:70-75. https://doi.org/10.1016/S1529-9430(01)00159-0

25. Glaser SE and Falco F. Paraplegia following a thoracolumbar transforaminal epidural steroid injection. Pain Physician. 2005; 8:309-314 https://doi.org/10.36076/ppj.2005/8/309

26. Alleyne $\mathrm{CH}$, Cawley CM, Shengelaia GG and Barrow DL. Microsurgical anatomy of the artery of Adamkiewicz and its segmental artery. J Neurosurg. 1998; 89:791-795. https://doi.org/10.3171/jns.1998.89.5.0791

27. Park JW, Nam SH, Cho SK, Jung HJ, Lee BJ and Park Y. Kambin's triangle approach of lumbar transforaminal epidural injection with spinal stenosis. Ann Rehabilitation Med. 2011; 35(6): 833-843. https://doi.org/10.5535/arm.2011.35.6.833

28. Crall TS, Gilula LA, Kim YJ, Cho Y, Pilgram T and Riew KD. The diagnostic effect of various needle tip positions in selective lumbar nerve blocks: an analysis of 1202 injections. Spine. 2006; 31:920-922. https://doi.org/10.1097/01.brs.0000209325.52986.da

29. Lee JW, Kim SH, Choi JY, Yeom JS, Kim KJ, Chung SK, et al. Transforaminal epidural steroid injection for lumbosacral radiculopathy: preganglionic versus conventional approach. Korean J Radiol. 2006; 7: 139-144. https://doi.org/10.3348/kjr.2006.7.2.139

30. Jeong HS, Lee JW, Kim SH, Myung JS, Kim JH and Kang HS. Effectiveness of transforaminal epidural steroid injection by using a preganglionic approach: a prospective randomized controlled study. Radiology. 2007; 245:584-590. https://doi.org/10.1148/radiol.2452062007

31. Hoshide R, Feldman E and Taylor W. Cadaveric analysis of the kambin's triangle. Cureus.2016; 8(2): e475. https://doi.org/10.7759/cureus.475

32. Gil HY, Jeong S, Cho H, Choi E, Nahm FS and Lee PB. Kambin's triangle approach versus traditional Safe Triangle Approach for Percutaneous Transforaminal Epidural Adhesinolysis Using an Inflatable Balloo Catheter. A Pilot Study. J Clin Med. 2019; 15:8(11) 1996

https://doi.org/10.3390/jcm8111996

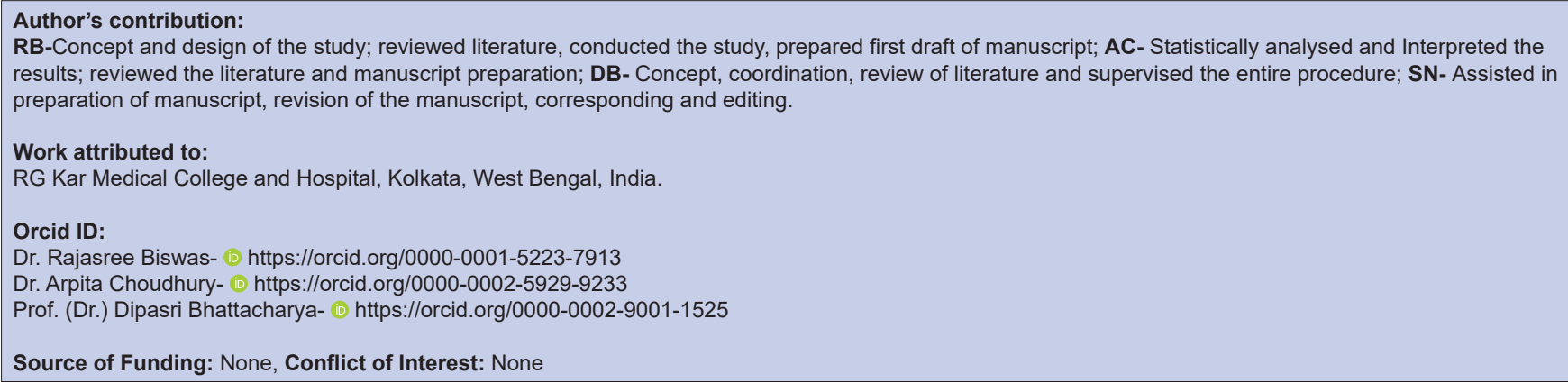

